\title{
DE LAS REDES SOCIALES AL PERIODISMO CIUDADANO Y LA CIBERDEMOCRACIA
}

\section{FROM SOCIAL NETWORS TO CITIZEN JOURNALISM AND CYBERDEMOCRACY}

\author{
Eduardo Fernández-Armendáriz \\ Universidad Autónoma de Chihuahua \\ efernandezarmendariz@gmail.com
}

\section{Resumen}

A través de análisis bibliográfico y experiencias periodísticas, se estudia el alcance ciberdemocrático del llamado periodismo participativo. En el proceso de gestación de este periodismo digital una nueva conceptualización de los procesos comunicacionales tiene lugar que integra términos como hipertexto, semiosfera, blogosfera, cibercultura, ciberperiodismo, ecosistema multimedia, web 2.0, wikis, democracia electrónica, ágora mediática o plataformas independientes. Finalmente se discuten las tendencias, oportunidades y obstáculos para el desarrollo de la ciberdemocracia, con las nuevas formas de acceso y participación de los actores sociales a la producción de información.

Palabras clave: Periodismo ciudadano, redes sociales, semiosfera, periodismo digital, weblogs, ciberdemocracia.

\section{Abstract:}

Via bibliographical analysis and journalistic experiences, I have studied the cyberdemocratic scope of so-called participative journalism. In the process of development of this digital journalism, a new conceptualization of the communication processes takes place that integrates terms such as hypertext, semiosphere, blogosphere, cyberculture, cyberjournalism, multimedia ecosystem, web 2.0, wikis, electronic democracy, media "agora" or independent platforms. Finally, trends, opportunities and obstacles for the development of cyberdemocracy are discussed in light of the new forms of access and participation of the social actors in the production of information.

Keywords: Participative journalism, social networks, semiosphere, digital journalism, weblogs, cyberdemocracy. 


\section{Introducción}

La red social Facebook al finalizar el año del 2012 contaba con más de mil millones de usuarios, en México con 47 millones $^{1}$, por lo que en diversos medios se planteaba que si fuera un país ocuparía el tercer lugar mundial después de China e India. Con Twitter, Google y otros sitos esta red social está convirtiendo al planeta en la "aldea global" profetizada por McLuhan.

El ciberespacio ha conformado una "ecología comunicacional" (Dennis de Moraes, Razón y palabra 37) al compartir todos un hipertexto formado por conexiones generalizadas que se organiza y se retroalimenta continuamente con una relación complementaria con lo real. Lo positivo de este espacio virtual es que los procesos de significación no se anulan sino que se añaden y se mezclan por lo que el periodismo impreso coexiste con la radio, la televisión y ahora con Internet. Esta combinación virtuosa permite el crecimiento exponencial de la información y de la capacidad de comunicarla a un mayor número de audiencias. Los receptores no solo captan la información sino que la pueden complementar con sus opiniones y más datos en forma infinita.

Al no existir sistemas semióticos en forma aislada que funcionen por sí solos, estos necesitan estar sumergidos en un continuo semiótico al que Lotman (1998) llama la semiosfera ${ }^{2}$. Es en este espacio semiótico donde se da la función comunicativa del texto en los siguientes procesos: entre el destinador y el destinatario, entre el auditorio y la tradición cultural, del lector consigo mismo, del lector con el texto así como del texto con el contexto cultural. Debido a que el contexto cultural es un fenómeno complejo y heterogéneo un mismo texto puede relacionarse de distintas maneras con diversas estructuras en los distintos niveles del mismo.

El texto no es un simple mensaje en un lenguaje determinado sino un complejo dispositivo que guarda diversos códigos por lo que es capaz de transformar los mensajes recibidos y de generar nuevos mensajes. El Ilamado hipertexto en Internet multiplica esta capacidad del texto en forma ilimitada por lo que al estar digitalizado se puede difundir por los diversos medios y a su vez ser vuelto a ser procesado-transmitido de nueva cuenta por la red y así hasta el infinito.

Un sitio en Internet puede así convertirse en la semiosfera donde cohabitan a la vez textos de otros medios como de radio, televisión, diarios, revistas así como otros documentos como videos, audios, DVD, libros, archivos, iconografías, etc. El ecosistema multimedia de la red permite lo que hasta hace poco era inimaginable, la convergencia de todos los medios en una sola plataforma digital. Esta cibercultura no se superpone a las culturas existentes ni las aniquila pues como lo enfatiza Moraes al ser dialéctica establece nexos e hibridaciones que activan desdoblamientos y remisiones en lugar de las tradicionales demarcaciones de las culturas tradicionales regidas por sus propios rasgos (lenguaje, religión, costumbres).

1 De acuerdo con datos proporcionados por Facebook correspondientes al cierre del mes de junio del 2013, los cuales indicaban también que eran 28 millones de usuarios mexicanos los que empleaban Facebook diariamente. Así, México se colocaba en el segundo país en Latinoamérica donde se utilizaba más esta red después de Brasil. El Heraldo de Chihuahua: 19.08.2013.

2 La semiosfera es el espacio semiótico fuera del cual es imposible la existencia de la semiosis, como lo sería la de un ser vivo fuera de su biosfera. 


\subsection{De los blogs a las redes sociales globales}

La utilización de blogs o bitácoras en línea es una forma revolucionaria y característica de la Web 2.0 ya que genera nuevas formas de informarse, comunicarse y participar en forma independiente. El ciudadano vuelve a ser el responsable del mensaje y la interactividad con otros usuarios permite una democratización de la información que difícilmente se puede dar en los otros medios de comunicación. Los internautas se convierten así en protagonistas activos y dejan de ser meros observadores pasivos.

Un ejemplo popular de los blogs son los wikis, sitios creados por algún usuario al que pueden entrar otros invitados para contribuir y modificar algún texto común, como lo es la Wikipedia, la más popular enciclopedia mediática. Hoy en día se habla de la blogosfera, derivada del inglés blogosphere, la cual comprende la totalidad de los weblogs. En la blogosfera es donde se crean y funcionan las redes sociales.

Con un enfoque más analítico otros comunicadores han resaltado el empoderamiento ciudadano a través de las redes. Los mexicanos Octavio Islas y Arturo Cano afirman que el desarrollo de la Web 2.0 es un parte aguas histórico en la evolución de Internet ya que el consumidor se ha estado convirtiendo en prosumidor gracias a la auto aplicación del conocimiento y al conocimiento aplicado a la revolución misma del conocimiento. Señalan que las redes sociales (Social Networking) son uno de los ambientes comunicativos más emblemáticos de la Web 2.0, a la mayoría de las cuales se puede ingresar en forma rápida y gratuita.

Facebook fue creada en el 2004 por Mark Zuckerberg y logró superar en agosto del 2008 a MySpace como la red social con mayor número de usuarios al registrar 132 millones, de los cuales el 62 por ciento se encontraban fuera de los Estados Unidos. Trejo Delarbre registraba que en octubre del 2008 Facebook contaba con más de 110 millones de usuarios regulares y consideraba a esta red como el quinto sitio más visitado de Internet después de Yahoo, Google, YouTube y Windows Live, por lo que se calculaba que esta red tenía un valor de 8 mil millones de dólares, lo cual le habría redituado a su creador nada menos que mil 500 millones de dólares (Razón y palabra, 66).

El crecimiento gigantesco de Facebook es evidente al llegar en el mismo 2009 a los 300 millones de usuarios, según lo informó su fundador Mark Zuckerberg en el mes de septiembre de ese año. Tal éxito, lo explica Andrés Roemer, se debe a que manifiesta nuestro instinto de caza (fue creado por Zuckerberg para ligar a sus compañeras de la universidad) así como nuestra necesidad de pertenecer a una tribu, en este caso incluso global. Roemer señala que el ser aceptado es una necesidad tribal así como todo el juego y el intento de ser amado es una necesidad vital. No deja de indicar el peligro que conlleva el hacer públicos datos personales pues como con los animales no humanos el riesgo de replicarnos para sobrevivir es el ser depredado por otros. Al ser la regla fundamental de la red social el consentimiento y la libertad solo limitada por el daño ajeno, comentaba que no sería extraño que Facebook se convirtiera en la verdadera aldea global (El Universal: 19.09.2009).

Las redes sociales también pueden ser docentes y de dos tipos, las institucionales y las autogestionadas por el profesorado. Para superar la brecha cognoscitiva sería benéfico si en el futuro se interrelacionaran estas comunidades del aprendizaje con las otras redes populares para gestionar y formar una opinión pública global. Información y conocimiento deben ir unidos en el proyecto universal de crear un nuevo y mejor tipo de hombre así como de sociedad. Las redes sociales son el embrión de 
las ilimitadas posibilidades existentes en la red para lograr la democratización de los saberes y poderes por ahora en manos de las elites.

\subsection{El periodismo ciudadano, ¿realidad o utopía?}

Al ser Internet utilizado por miles de redes constituidas por millones de usuarios para su interactividad diaria era lógico que el periodismo también empleara este nuevo medio de comunicación para lograr una mayor interactividad e influencia en el público. El surgimiento del periodismo online incrementó la esperanza de que por primera vez se pueda ejercer un periodismo libre y crítico sin depender de los medios tradicionales sujetos a intereses políticos y económicos.

El periodismo digital inicia el 19 de enero de 1994 con la aparición de la primera edición digital en la Web de la revista electrónica Palo Alto Weekly, una publicación ya con historial en la población homónima ubicada en la Bahía de San Francisco. La multiplicación exponencial de los cibermedios periodísticos se dio en toda la red y así Yahoo! ya registraba en el 2005 más de 9 mil ediciones digitales de diarios impresos en todo el mundo. Salaverría afirma que el equipo investigador en el que participó había detectado a fines del 2004 más de 1,400 publicaciones digitales en España, por lo que suponía era mayor aún la cifra de medios periodísticos en la red que los localizados por Yahoo!. El investigador portugués consideraba que ya en esas fechas los europeos le dedicaban más tiempo (el 20\%) a leer información en Internet que el utilizado por quienes leían diarios impresos $(11 \%)$ y revistas impresas $(8 \%)^{3}$.

La principal virtud del ciberperiodismo es desde luego la interactividad, la cual es casi inexistente en los demás medios. El usuario ya no es el lector pasivo sino que pasa a ser partícipe de los sucesos al opinar, valorar y retransmitir los documentos periodísticos. Así, por ejemplo, si uno lee una nota de interés la puede bajar y reproducir a cientos o miles de usuarios en la red, agregándole comentarios e información complementaria. Incluso el ciudadano común se puede convertir temporalmente en periodista al grabar algún hecho y enviarlo a un medio, el cual a su vez será visto por millones de usuarios y reproducido a su vez por otros medios. Para los ortodoxos del periodismo ésta es una herejía, pero si se parte del principio de que la información es análoga a lo que es la democracia, esto es, debe ser para todos, entonces su uso deja de ser exclusivo de minorías y se convierte en propiedad de las mayorías. Una sociedad desinformada es fácilmente manipulable, por lo que si continúa este empoderamiento ciudadano de la información repercutirá sin lugar a dudas en la democratización de las instituciones y en una ampliación de los derechos de los ciudadanos, como la libertad de expresión.

Otra de las grandes ventajas del periodismo digital es la accesibilidad pues en cualquier tiempo y desde cualquier sitio del mundo se puede conectar al medio periodístico en la red para consultar alguna información. Lo mismo a través del teléfono celular que con una computadora se recibe y transmite información inmediata, lo cual difícilmente se puede lograr con los otros medios electrónicos y menos con los impresos. Al contar la mayoría de los medios periodísticos con una hemeroteca digital se facilita también la indagación sobre un hecho pasado y es más sencillo comprobar algún dato. El usuario se convierte así en investigador aficionado pero con el tiempo puede adquirir habilidades parecidas a las de un profesional, lo cual desde luego le permite una formación personal continua y sobre todo una visión más completa de su entorno. Al ser más accesible no solo la información sino también el conocimiento, el

3 Ver Ramón Salaverría, "Construyendo un nuevo periodismo. Diez años de logros y retos en la prensa digital." Comunicaçao e Sociedade, vol. 9-10, 2006, pp. 129-137. 
lector tiende a dejar de ser pasivo para convertirse en activo y con un mayor interés periodístico.

Por otra parte, tanto la hipertextualidad como la multimedialidad no solo enriquecen la información sino la convierten en un proceso infinito y multiplicador al dejar de estar centralizada por el medio para convertirse en común, lo cual es a fin de cuentas la comunicación. Los medios habituales son considerados en forma crítica más como de información que de comunicación pues raramente transmiten la retroalimentación por parte de sus receptores, lo cual puede ser superado por los medios digitales al incluir las opiniones de sus usuarios e influir en la presentación y organización de la misma información. El problema ahora no es la escasez sino la abundancia de información, buena parte de la cual es poco fiable y menos confiable.

\section{El periodismo digital y la participación ciudadana}

El periodismo digital se puede dividir en dos tipos: en la red y de la red. El primero consiste en la versión digital de los medios convencionales, principalmente de la prensa, así como a las publicaciones online que imitan el modelo de edición de un medio impreso. El segundo tipo consiste en sitios informativos concebidos para y desde la red, el cual es cuestionado sobre si es o no realmente periodístico ya que el primero sí lo es aunque tenga un soporte distinto al papel. La razón de que se defina o no a estas publicaciones de la red como periodismo consiste en que ya no dependen de una periodicidad, esto es, su aparición no está limitada a un tiempo específico como es el caso de los diarios y revistas impresos. Otra razón para dudar de su calidad periodística es su dudosa confiabilidad pues debido a que los reporteros suben inmediatamente la nota a la página no cuidan la calidad ni prueban su veracidad, lo que no sucede en las redacciones de prensa. Sin embargo, en términos generales la mayoría de las publicaciones en la red o de la red siguen el formato clásico de la edición periodística y cumplen con los requisitos para que una información sea periodística.

\subsection{Contenidos de los periódicos digitales}

Luis A. Albornoz (2006) analizó a seis de los principales diarios online iberoamericanos $^{4}$ y encontró las siguientes características comunes en los contenidos informativos, mismas que se pueden aplicar al resto de los periódicos digitales:

- Información noticia: Al ser la de mayor caudal y renovarse con mayor periodicidad se le puede considerar como el núcleo de los diarios digitales. La información noticia es ordenada en secciones, suplementos y portales verticales. Las dos primeras son heredadas de la prensa impresa mientras la última es propia de Internet pues incluye herramientas web como buscadores, enlaces, blogs, foros, etc.

- Últimas noticias: la actualización permanente acerca a los periódicos online al patrón de funcionamiento de la radiofusión y al modelo de las industrias culturales. La actualización depende del personal empleado específicamente para esta labor por parte de los diarios pues mientras Elmundo.es empleaba 45 profesionales en su redacción el $A b c$.es solo utilizaba a ocho periodistas. La diferencia se refleja en que Elmundo.es se destaca porque sus secciones están conformadas

4 ElMundo.es, ElPaís.es, Abc.es, Clarin.com, LaNación.com y Reforma.com. 
por contenidos exclusivos de su redacción mientras los otros diarios iberoamericanos combinan contenidos de la edición impresa y de la digital.

- La edición impresa en la red: La mayoría de los diarios, excepto Reforma, tienen libre acceso a la portada del día. Los seis cobran por la versión PDF de su edición impresa y algunos también cobran el acceso a sus contenidos en lenguaje HTLM como EIMundo.es, Reforma.com y El País.es. Los otros tres incluyen en formato HTLM los contenidos de sus ediciones impresas sin costo alguno.

- Suplementos y secciones especiales: Excepto el Abc.es, los diarios analizados presentan informaciones especiales agrupadas en suplementos, los cuales son un reflejo de su existencia en papel aunque en la red son actualizados en el mismo día en que son impresos. Las secciones especiales como directorios informativos, informes multimedia, gráficos animados y paseos virtuales.

- Coberturas en tiempo real: Los diarios ofrecen información en tiempo real de acontecimientos relevantes así como de operaciones bursátiles, aunque aún no pueden competir en inmediatez y oportunidad con la radio y la televisión. Su ventaja con estos medios es que la información es accesible en cualquier momento y aumentada continuamente por lo que el lector puede contar con una mayor y más detallada cobertura de los hechos. Debido a esta versatilidad la mayoría de las radiofusoras y televisoras también suben sus contenidos a sus sitios en la red para competir en este aspecto con los diarios digitales.

- Ranking de noticias: Es un tipo especial de información que se construye automáticamente en el transcurso de horas a partir del recorrido del recorrido de los visitantes a las páginas digitales. Si en los periódicos impresos es prácticamente imposible detectar el número de lectores de sus secciones, en cambio en los diarios digitales se puede llevar un conteo preciso como lo hacen algunos sitios. El más completo es el del EIPaís.es, pues tiene un ranking de las últimas 24 horas, siete días y 30 días organizados en varias categorías.

- Bitácoras o weblogs: Elmundo.es y visibilidad eran los únicos que contaban con una sección específica para estos contenidos informativos aunque no usaban la información de este tipo de otras fuentes digitales de la red. En la actualidad la mayoría de los diarios y revistas digitales no solo incluyen una sección para blogs sino también tienen enlaces con redes sociales como Facebook y Twitter.

\subsection{Participación activa del usuario en el periódico}

Un factor importante en esta nueva faceta del periodismo es la participación activa del usuario de la red para no solo recibir la información sino también para generarla e incluso modificarla dando lugar a lo que se ha denominado comúnmente como periodismo ciudadano. José María Percival señala que el vocablo "periodismo ciudadano" podría ser un oxímoron (palabra formada por dos términos que se contradicen) ya que el periodismo está incluido en la ciudadanía pero no al contrario, esto es, todos los periodistas son ciudadanos pero no todos los ciudadanos son periodistas (Anàlisi 36:79-86). Hay que señalar que la interpretación de Percival no es acorde con el sentido habitual en que se usa el término periodismo ciudadano.

La reivindicación del periodismo cívico ya era plantada en cierta forma por John Dewey en su réplica en contra de Lippman (Nuria Almiron Roig, Revista Latina de Comunicación Social 61) al defender que los ciudadanos deberían discutir públicamente los temas una vez que hubieran sido informados de ellos sin alguna manipulación. Dewey aceptaba al igual que Lippman la profesionalización tanto de la política 
y del periodismo, pero consideraba que la falta de confianza del periodista norteamericano en la democracia participativa se debía a su falta de imaginación. El filósofo estadounidense proponía precisamente para superar las dificultades inherentes más imaginación, cultura y educación. Volvemos así a la función formativa que debe tener el periodismo pues usualmente se le limita en aras de una objetividad cada vez más cuestionada y objeto de suspicacias debido a su manejo intencionado por parte de los directivos de los corporativos mediáticos. Si la información es poder, en manos de unos pocos no deja de ser la antítesis de lo que sería una democracia.

Jarque Muñoz y Almiron-Roig (Palabra Clave 2) citan algunas de las principales objeciones que le hacen al periodismo ciudadano los periodistas veteranos y de conocida trayectoria profesional:

- Muchos blogs ocultan "un apoyo, e incluso una financiación, de ideología nada neutra, mientras la mayoría confunden la ausencia de fuentes de financiación con la ecuanimidad, la objetividad o la equidad" (Almirón, 2006).

- La visibilidad (o ausencia de), que para Francis Pisani (2006) es "la otra cara del mito, según el cual basta con crear un sitio para que lo vengan a visitar de todos los rincones del mundo" (Pisani, 2006).

- El carácter marcadamente personal de la herramienta o el "egocentrismo innato que se asocia y genera en la actividad blogosférica, que permite que el número de lectores de un blog o bitácoras sea mayoritariamente poseedor de otro blog, con lo que prácticamente no existen los lectores puros" (Cantalapiedra y Morán, 2006).

- En las experiencias de periodismo ciudadano más exitosas, como el portal Oh my news!, no sólo hay periodistas profesionales sino que estos se encargan de valorar qué noticia es más importante y de interpretar el artículo correctamente, tal y como relató su fundador, Oh Yeon Ho (2005), en una entrevista.

Como lo citan estos comunicadores, un ejemplo del nuevo tipo de periodismo interactivo es el diario digital coreano OhMyNews! que emplea como reporteros a miles de ciudadanos bajo la supervisión última de periodistas (Xosé López García, Estudios sobre el mensaje periodístico 2007: 117). El éxito de este experimento prueba que la participación ciudadana en la actividad periodística es al parecer una tendencia irreversible por lo que los medios informativos deben tomarla en serio y adaptarse a ella si desean sobrevivir. Tal incursión de los usuarios en un ámbito antes exclusivo de los periodistas profesionales no debe constituir por sí mismo un riesgo de que desaparezca el periodismo como oficio pues continuará ejerciendo su papel de intérprete de la realidad. Claro que para ello el periodista deberá adaptarse a las nuevas circunstancias, como lo ha hecho en ocasiones pasadas ante los cambios tecnológicos y sociales, y tomar más en cuenta las opiniones del público y no solo las usuales de las fuentes tradicionales.

En España también funciona un diario vasco, El Correo, el que se ha convertido en modelo de participación ciudadana con su sección titulada enlaCe ${ }^{5}$, por lo cual al parecer es considerado como un ejemplo original y pionero en este país. Además de ser el primer periódico español estatal en recibir un premio internacional por su

5 Ver Mendiguren-Galdospin, Terese; Canga-Larequi, Jesús. Análisis de la participación ciudadana a través de un pionero modelo participativo en prensa: el proyecto "enlaCe" de El Correo. Estudios sobre el mensaje periodístico, ISSN-e 1134-1629, № 18, 1, 2012, págs. 133-146. (pdf Mendiguren 2012) 
filosofía de participación y colaboración del lector ha servido de ejemplo para otros diarios de Argentina, Alemania y de los Emiratos árabes.

El periodismo digital será cada vez más interactivo, pero desde luego más exigente para los responsables de la difusión informativa. Ahora el profesional de la información tendrá que aprovechar las herramientas que proporciona Internet para motivar la participación y conexión de las comunidades con los cibermedios, pero sobre todo deberá guiar al usuario sobre lo importancia de la información, su contexto y su trascendencia en el ámbito social. El periodista tendrá también un rol educativo por lo que su nuevo perfil debería contemplar también el de ser un intérprete de la realidad aplicando la filosofía en forma cotidiana y comunicándola en lo posible en forma literaria, esto es, con un lenguaje adecuado y de manera estética.

Dos investigadoras de la Universidad Autónoma de Barcelona proponen que un prototipo de periodismo digital para la participación ciudadana efectiva debería cumplir fines como: mejorar la calidad humana y periodística de la información política y con ello de la actividad de la ciudadanía plural en la democracia, otorgar a cualquier individuo la posibilidad de ser un protagonista activo para participar en la evolución de las políticas públicas y de la acción gubernamental, así como de generar nuevos procedimientos para registrar y difundir la información política y la gestión de la administración pública. Para ello el periodismo digital debería desarrollar innovaciones en la recogida de información, en el contraste de fuentes así como en la elaboración, presentación y difusión de la información periodística (Amparo Moreno Saardá y Nuria Simelio Salá, Anàlisi 36: 115-129).

\section{La ciberdemocracia y la mega ágora mediática}

La democracia concebida comúnmente como "el gobierno del pueblo, por el pueblo y para el pueblo"6 es un ideal político cuestionado y cuestionable, pero el cual con sus virtudes y defectos continúa siendo la principal guía de las luchas sociales en contra de la dictadura, ya sea de un hombre, un grupo o de una nación sobre otras. La democracia de la soberanía popular antigua ha transitado a la representatividad ciudadana en la modernidad y en la actualidad se ha convertido en un gobierno de opinión, como la define Giovanni Sartori (2007). El politólogo considera que al ser la democracia el gobierno del pueblo sobre el pueblo, esto es parte gobernante y parte gobernada, será la primera cuando vota y serán las elecciones donde se haga el cómputo de las opiniones de los ciudadanos. Las elecciones por consiguiente son un medio cuyo fin es el "gobierno de opinión". Afirma que todo el edificio de la democracia se apoya en la opinión pública ${ }^{7}$ más que en el saber (episteme), como lo propusiera Platón con su ideal del filósofo-rey.

Pues bien, este gobierno de opinión se ha complementado con el funcionamiento de Internet para constituir un nuevo tipo de democracia, la ciberdemocracia. Llamada también democracia digital, democracia electrónica o democracia online, la ciberdemocracia es el ejercicio del usuario de la red de transmitir libremente sus opiniones, coordinarse con otros cibernautas para llevar a cabo acciones de índole política, manifestarse a favor o en contra de algún candidato y llevar a cabo actividades de

6 Como la definiera Abraham Lincoln en su discurso pronunciado en Gettysburg.

7 El pensador italiano señala que "opinión pública" denota un público interesado en la "cosa pública" o sea la res pública. Así la opinión será pública no solo porque es del público sino porque afecta asuntos que son de naturaleza pública como el interés general y el bien común. Giovanni Sartori, ¿Qué es la democracia?, pp. 71-73. 
proselitismo para alguna causa social, por ejemplo, para evitar el calentamiento global. El predominio que ejercían los medios masivos de comunicación, sobre todo la televisión, en la formación de la opinión pública se ve ahora amenazado seriamente por su más fuerte y creciente competidor, la red de redes.

\subsection{Aplicación de los criterios de Dahl a la ciberdemocracia}

La ciberdemocracia parece cumplir con los criterios señalados por Dahl que deben ser satisfechos para que una asociación sea considerada como una democracia: la participación efectiva, igualdad de voto, alcanzar una comprensión ilustrada, ejercitar el control final sobre la agenda y la inclusión de los adultos. ${ }^{8}$

La participación efectiva consiste en que todos los integrantes de una asociación puedan manifestar sus puntos de vista antes de que pueda ser adoptada una política. A través de la red son más los ciudadanos que pueden manifestar rápidamente sus opiniones que los entrevistados por alguna encuesta directa o a través de los medios. Basta con conectarse para enviar de inmediato un mensaje, ya sea a través de una computadora o un teléfono celular. La facilidad para realizar el conteo digital también crea una mayor confiabilidad sobre el parecer mayoritario sobre algún asunto público.

En relación al segundo criterio, el voto es igual en la red pues se parte del principio que todos los usuarios son en principio iguales por lo que cuentan de la misma forma. Son innumerables las encuestas que actualmente se realizan por Internet en distintos sitios, cuyos resultados son significativos y confiables para ser utilizados y difundidos por otros medios para crear opinión pública.

El tercer aspecto sobre la comprensión ilustrada consiste en que todo miembro debe tener las mismas oportunidades para informarse sobre las políticas alternativas relevantes y sus posibles consecuencias. ¿Dónde si no es en la red donde el ciudadano puede tener un mayor acceso a la información y al conocimiento de las distintas propuestas así como de sus pros y contras? El acceso libre por lo pronto está garantizado al menos en los sistemas democráticos pues en países como China se restringe el uso en Internet hasta de la palabra democracia.

Respecto al cuarto criterio, el de ejercitar el control final de la agenda, se refiere a que los miembros pueden decidir el cómo y qué asuntos deben ser incluidos en la agenda por lo que las políticas deberán estar siempre abiertas a los cambios introducidos por los participantes. Al superar las limitaciones de espacio y tiempo en los sitios de la red las distintas opiniones influyen indefinidamente en el tratamiento de los temas más relevantes y empiezan a definir la agenda de los otros medios así como de la mayoría de los políticos. Hoy en día es raro el comunicólogo o el activista político que no esté conectado a Internet, sobre todo a una red social, y no tome seriamente en cuenta el parecer expresado por los usuarios. No se diga ya el rol jugado por los movimientos sociales globales, los cuales a través de la red se ponen de acuerdo para participar con alguna manifestación en algún lugar definido y hasta a una hora precisa.

Por primera vez en la historia la opinión pública cuenta con un mensajero eficaz y por consiguiente cada día más poderoso que amenaza con relevar a los usuales conductores y formadores de la misma. En Internet la tendencia es centrífuga, no centrípeta, como sucede con la concentración mediática ya comentada en el segunda parte de este texto. ¿Cuánto durará este ciberespacio libre y espontáneo sin ser controlado

8 Robert Dahl, La democracia, pp. 47-49. 
por los grandes consorcios políticos y económicos? La respuesta como en el caso de la democracia la tienen los ciudadanos.

La inclusión de todos los adultos o al menos la mayoría de ellos es el quinto y último criterio especificado por Dahl. Aunque salvo algunos sitios reservados para mayores de edad, el acceso a Internet es libre para cualquier persona sin distinción de algún tipo. Claro que la restricción como en el mercado libre es el tener que pagar por algunos servicios específicos o especializados, o padecer la apabullante lluvia de comerciales, pero la selección y sobre todo el poder visitar innumerables sitios para informarse es casi igual para todos. Si antes se requería contar con cierto poder adquisitivo para poder leer los diarios y revistas, ahora se puede hacer en forma gratuita en la mayoría de los casos y no se diga el consultar una serie ilimitada de libros. La inclusión cada vez mayor de usuarios en la red demuestra que la brecha digital tiene visos de ser superada más pronto que la tradicional brecha económica entre ricos y pobres. Si ahora son la mayoría los televidentes en cualquier país que los consumidores de otros medios, en poco tiempo lo serán los internautas si se continúan aplicando las políticas de expansión planteadas por los organismos internacionales públicos y privados.

\subsection{Perspectiva de otros autores: ciberdemocracia y opinión pública}

Hoff, Harrod y Top (2000) caracterizan a la democracia electrónica en cuatro tipos: democracia de consumidores, democracia elitista, democracia neo-republicana y cyberdemocracia. A la primera la consideran como neoliberal, a la segunda pluralista, a la tercera republicana-socialdemócrata y a la última comunitarista radical. En la cyberdemocracia las comunidades virtuales y las redes se convertirían en el principal nexo de intermediación entre ciudadanos así como entre estos y los poderes políticos. En ella el sentido de pertenencia a una comunidad plural de identidades múltiples es condición básica, esto es, sería multicultural y deliberativa, Asimismo, en ella la asimilación de las nuevas tecnologías por parte de la política tendería a valorar a los medios de expresión de la opinión pública. Lo anterior influiría a la prensa virtual para que se guiara por procedimientos más transparentes y racionales que realmente representen la expresión auténtica de los ciudadanos. La retroalimentación sería un factor decisivo para este logro, lo cual difícilmente se puede dar con efectividad en los otros tipos de democracia citados.

Ahora bien, esto no significa que la ciberdemocracia sea mejor o superior a otras formas pues la ciberdemocracia es complementaria de la democracia, pero también transformadora de las formas habituales de tomar en cuenta a la opinión pública. Por ejemplo la llamada democracia neoliberal tiene de positivo la libertad de elegir para el consumidor, la elitista el ser pluralista y crear consensos así como la neo-republicana la participación y el debate público. Al igual que sus virtudes también tienen sus defectos como lo sería la exclusión y marginación, la primera de acuerdo al poder adquisitivo, la segunda en la formación de élites burocráticas y políticas mientras que en la tercera las desigualdades efectivas para la deliberación y el debate público. En la ciberdemocracia la marginación se daría entre conectados y desconectados así como de acuerdo a su nivel de información y conocimiento.

El problema que se plantea para que funcione una ciberdemocracia es parecido al de la implantación de la democracia en la sociedad: la participación ciudadana en igualdad de condiciones y la resistencia de los poderes fácticos. Los medios de comunicación son reacios a los movimientos populares debido a los intereses creados, principalmente con sus patrocinadores (gobiernos y empresas), por lo que restringen la difusión de la actividad ciudadana o la manipulan de acuerdo a su política 
comunicativa. La red de redes rompe con este esquema pues cualquier individuo o grupo puede transmitir su información utilizando las conexiones con otros usuarios y obligando a los medios a cubrir el evento ante la repercusión noticiosa del hecho. La repetida frase de que cada ciudadano es un informador se está convirtiendo en realidad gracias al uso de Internet y este fenómeno desde luego dinamiza a los medios haciéndolos modificar su agenda.

La interrogante que surge es si se podrá efectivamente transitar a la democracia por medio del periodismo ciudadano. La función tradicional de los medios era informar, formar y entretener, pero al ocupar un espacio político como cuarto poder es obvio que dejaron a un lado la formación para hacer de la información un entretenimiento que aumentara sus audiencias y por ende su influencia o sea su poder político y económico. Con el objetivo de superar esta carencia de los medios de comunicación tradicionales Pau LLop (Razón y palabra 54) propone que los nuevos medios logren convertir a las audiencias en usuarios, para lo cual deben rescatar la función de formación entendida como la alfabetización digital del visitante. Un nuevo medio, afirma la periodista española, debe llevar en sus genes el periodismo ciudadano y no ser este un añadido o mejora como lo promocionan los medios tradicionales. El usuario debe por consiguiente aprender a usar las nuevas herramientas que le ofrece el medio, ser guiado para consultar las fuentes más adecuadas y exigir a sus autoridades la información a la que tiene derecho como ciudadano.

Pau LLop considera que además de convertir a las audiencias en usuarios los nuevos medios periodísticos deberían tener otra estructura, la de una red social de noticias, o sea una Info-social Network. Tal cambio, aclara, no conlleva la desaparición del periodista profesional ni de la redacción, pero sí la necesidad de su transformación para poder adaptarse a esta nueva estructura. Si la sociedad de la información tiene una estructura de red, como lo plantea Manuel Castells (2001), ¿por qué no la deberían tener los medios emergentes en Internet?

\subsection{La blogosfera como ágora}

La democratización de los medios no ha sido posible debido a la creciente concentración mediática y los intereses particulares de los propietarios, por lo que el surgimiento de nuevos medios con estructuras más abiertas y menos centralizadas permitiría no solo una mayor competencia sino también la organización ciudadana a través de las redes. Los medios cumplirían así en forma más eficaz con su responsabilidad social no solo de informar sino también de formar, pero sobre todo serían realmente medios para lograr construir una sociedad más democrática y por ende equitativa.

Habermas (2002), basándose en Rousseau, considera que la principal característica de la democracia es su ideal participativo, es un modelo político en el cual la legitimación de las decisiones se basa en la participación de todos o en lo que el ginebrino denominó como voluntad general. Según el filósofo alemán los medios son los que deberían crear el espacio público, pero su propia estructura y funcionamiento se los impide debido a que obedecen más a sus intereses económicos y políticos que a su responsabilidad de facilitar la libre expresión de los ciudadanos para crear la opinión pública. Habermas considera que si bien los medios tienen un potencial autoritario de control social su estructura comunicativa tiene un potencial de contrapeso para emanciparse de ese control. Por ello afirma que entrelazado el mundo de la vida con el espacio público va a ser este el lugar donde la sociedad plantea y reflexiona sus problemas así como sus soluciones, a la vez que critica al orden establecido. 
¿Será acaso la blogosfera el espacio del que habla el pensador germano más que el creado por los diarios digitales, o acaso sería factible una combinación virtuosa de los dos para potenciar la interactividad ciudadana?

En Internet se conjuga la interactividad y conexión con el mundo vida, por lo que este medio es un dinamizador de la esfera pública y un espacio público que puede enriquecer tanto al periodismo como democratizar el debate público. Ya no es un ágora limitada a una comunidad pequeña y cerrada propia de las antiguas democracias atenienses sino un conglomerado ilimitado de millones de foros públicos en los que participan decenas si es que no centenas de millones de usuarios de todo el mundo.

El problema es si esta mega ágora mediática puede funcionar como creadora de instituciones democráticas. La opinión pública continúa siendo modelada y manipulada por los medios tradicionales, sobre todo por la televisión, por lo que aún no se puede hablar de una ciberdemocracia basada y estructurada en la discusión libre y crítica de los usuarios. El riesgo es la fragmentación si es que no pulverización del discurso político que pude devenir en charlatanerías y divagaciones irracionales, mismas que a su vez pueden ser aprovechadas por grupos subversivos e ilegales para atacar las instituciones democráticas. La anarquía intelectual es saludable pero lo es más la construcción cognoscitiva de un pensamiento racional que guíe y ayude a encontrar las alternativas viables para enfrentar los problemas y riesgos de esta nueva era.

\section{Los weblogs, una opción para superar la concentración informativa}

Una alternativa que podría ser viable para evitar la concentración de la información y el poder por parte de los medios tradicionales es la comentada por Núria Almiron, las plataformas independientes, a las cuales considera como el embrión de un quinto poder. Las plataformas independientes son utilizadas para difundir el periodismo de investigación no corporativizado y por diversos agentes no gubernamentales (como observatorios ciudadanos) para vigilar a los medios de comunicación.

Algunas de estas publicaciones digitales independientes más influyentes son Nieman Reports, creadora de Watchdog Proyect para vigilar al poder político, Columbia Journalism Review y American Journalism Review. Entre los observatorios de los medios de comunicación se encuentran el Media Global Watch creado en el Foro Social de Porto Alegre en el 2003, así como los vinculados a varias universidades como la Autónoma de Barcelona.

Además de estas plataformas independientes la participación ciudadana en el periodismo digital se manifiesta principalmente a través de los weblogs. Una de las principales causas de su difusión es que han adquirido un buen posicionamiento en Google y otros buscadores lo cual tiene como resultado que muchas búsquedas den como resultado páginas weblogs. La razón de que ello es que los blogs utilizan tecnologías que permiten indexarlos eficazmente y su enorme cantidad de vínculos les permite tener altos grado de ranking de resultados de los buscadores, los cuales para ordenar los vínculos toman en cuenta la cantidad de enlaces en un sitio. Otro factor que ha propiciado el surgimiento de los weblogs es la gratuidad en la publicación como el alojamiento en el sitio.

Los weblogs, diarios de navegación o bitácoras se están consolidando en Internet como alternativa de los diarios digitales. En algunas carreras de universidades norteamericanas, como la de Periodismo en Berkeley y la de Comunicación de Annen- 
berg (Universidad de California) incluyen los weblogs en sus planes de estudios como una nueva forma de periodismo (Manuel Frascaroli, Hologramática 10: 69-86). Los weblogs, como ya se mencionó anteriormente, son sitios en Internet en los cuales se publican comentarios y opiniones sobre diversos temas y son actualizados con cierta regularidad por la persona creadora o responsable de la página blog.

Los bloggers (autores) recopilan noticias de la red, las suben al weblogs, otros usuarios exponen sus comentarios, de tal forma que se convierten en periodistas-editores. De esta forma como lo afirma el profesor Dan Gillmor, "cualquier persona en cualquier parte del mundo puede convertirse en un reportero ciudadano por medio de un móvil o un ordenador, y la extensión del derecho a la información nos conduce a una sociedad sin secretos." (Antonio García Jiménes y Paloma Rúperez Rubio 2007).

Al principio los blogs servían como sitio de enlaces pero se fueron transformando como medios para informar, opinar, contar las historias personales, exhibir colecciones de fotos, etc. La diversidad de los usos de los weblogs los convierten en algo más que medios informativos, sin embargo ya existen los que se enfocan solo a este ámbito. Los weblogs compiten con los diarios digitales debido a su dinámica y versatilidad, así como a la interacción de sus usuarios. Así, el éxito de Twitter se debe a la limitación de que solo se pueden transmitir 140 caracteres en un microblogging, lo cual facilita la comunicación inmediata entre los que están conectados, lo cual incrementó el número de usuarios de esta red a 18 millones en solo tres años desde que fue fundada por el ingeniero en informática Jack Dorsey.

La activa participación de los bloggers ha influido para que diarios como el Dallas Morning News diera a conocer a sus lectores en un blog el proceso de toma de decisiones de la junta editorial sobre las noticias. Otros de los principales diarios en línea como el The Wall Street Journal, el San José Mercury News, The Boston Globe o la cadena de televisión FoxNews destinaban uno o varios periodistas para que contestaran los blogs emitidos por sus usuarios. Incluso algunos periódicos en Estados Unidos y España han captado periodistas-bloggers para sus primeros espacios en sus ediciones digitales y por otra parte algunos bloggers han adquirido legitimidad como fuente, tal es el caso de Garret Graff, pseudónimo del primer autor de un blog acreditado como corresponsal en la Casa Blanca de un medio desconocido: Talo News service (Manuel Frascali, Hologramática 10).

\section{Conclusiones}

El ciberespacio ha conformado una ecología comunicacional ya que permite el crecimiento exponencial de la información y de la capacidad de comunicarla a un mayor número de audiencias. Es en la semiosfera donde se da la función comunicativa del texto y el hipertexto multiplica la capacidad del texto en forma ilimitada. Por ello un sitio en Internet puede convertirse en la semiosfera donde cohabitan a la vez textos de otros medios como la radio, televisión, diarios, revistas y de otros documentos como videos, audios, DVD, libros, archivos, iconografías, etc.

Esta emergente cibercultura no se superpone a las culturas existentes ni las aniquila pues al ser dialéctica establece nexos e hibridaciones que activan desdoblamientos y remisiones en lugar de las tradicionales demarcaciones de las culturas tradicionales. El ciberespacio es una gigantesca semiosfera compartida y abierta por lo que se ha transformado en un espacio público de libre debate de opiniones e ideas que es utilizado no solo por los corporativos públicos y privados sino también por la sociedad 
civil global. La blogosfera es la zona más dinámica y participativa de los usuarios, sobre todo de los que están organizados en redes sociales.

El periodismo digital en esta nueva semiosfera será cada vez más participativo, interactivo, pero desde luego más exigente para los responsables de la difusión informativa. Ahora el profesional de la información tiene que utilizar las herramientas que le proporciona Internet para motivar la participación y conexión de las comunidades con los cibermedios, pero sobre todo debe guiar al usuario sobre la importancia de la información, su contexto y su trascendencia en el ámbito social.

Una de las funciones principales del periodismo digital para poder fortalecer la democracia es la de ser guía e intermediario entre la cotidianidad documentada del mundo y su interpretación adecuada por parte de especialistas en la sociedad de la información. Para lograr este cometido se requiere fortalecer los vínculos directos así como la interactividad entre los periodistas y los ciudadanos (sociedad civil) sin la intermediación de los corporativos mediáticos y menos de los gobiernos. Lo único predecible de este nuevo panorama global es su continua, sorpresiva y explosiva creatividad que rompe con todos los paradigmas creados hasta ahora por la humanidad.

\section{Referencias bibliográficas}

Albornoz, Luis A (2006). Periodismo digital. Los grandes diarios de la red. Buenos Aires: Ediciones La Crujía.

Castells, Manuel (2001) La era de la información: Economía, sociedad y cultura. Volumen I: La sociedad red, México: siglo veintiuno editores.

Dahl, Robert (1999). La democracia. Una guía para los ciudadanos. Madrid: Taurus.

García Jiménez, Antonio y Paloma Rupérez Rubio (editores). (2007) Aproximaciones al periodismo digital, Madrid: Editorial Dykinson.

Habermas, J. (2002) Historia y crítica de la opinión pública. La transformación estructural de la vida pública, Barcelona: G.Gili.

Hoffs, J., Horrocks, I and Tops, P. (eds.) (2000). Democratic Governance and New Technology. London: Routledge/ECPR Studies in European in Political Science.

Lotman, Yuri M (1998). La semiosfera II. Semiótica de la cultura, del texto, de la conducta y del espacio, Madrid: Ediciones Cátedra.

Sartori, Giovanni (2008). ¿Qué es la democracia? (nueva edición revisada y ampliada), México: Taurus.

\section{Sitios en Internet:}

Análisi. Revista del Departamento de Ciencias de la Comunicación de la UAB. http://uab. es

Comuncâo e Sociedade. http://revocom.portcom.intercom.org.br

El Universal. www.eluniversal,com.mx.

Estudios sobre el mensaje periodístico. Portal de revistas científicas complutenses. http:// revistas.ucm.es 
Hologramática. Revista de Ciencias Sociales, Comunicación, relaciones Laborales, Literatura, Educación y Trabajo Social. Facultad de Ciencias Sociales UNLZ. ISSN 16685024. www.cienciared.com.ar

Palabra Clave. Revista de la Facultad de Comunicación de la Universidad de La Sabana. ISSN: 0122-8285. http://educacionyeducadores.unisabana.ed.co

Razón y palabra. Primera revista latinoamericana especializada en comunicación. Tecnológico de Monterrey, ISSN 1605-4806, www.razonypalabra.org.mx.

Revista Latina de Comunicación Social. Editada por el Laboratorio de Tecnologías de la Información y Nuevo Análisis de Comunicación Social. Universidad de La Laguna, Tenerife, España. ISSN: 1138-5820. www.ull.es 